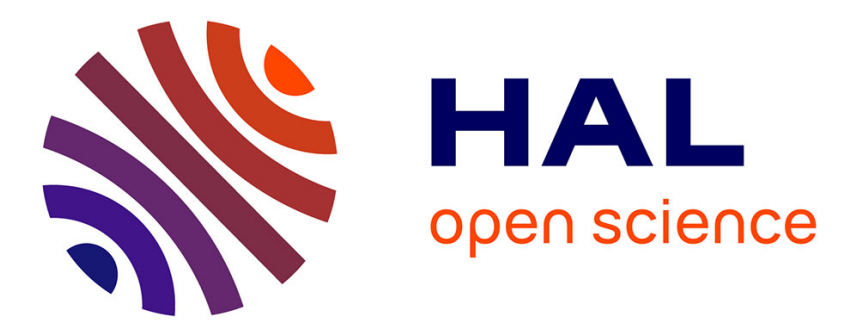

\title{
New karyotypic data for Asian rodents (Rodentia, Muridae) with the first report of B-chromosomes in the genus Mus.
}

Daleen Badenhorst, Vincent Herbreteau, Yannick Chaval, Marie Pages, Terence J. Robinson, Worawut Rerkamnuaychoke, Serge Morand, Jean-Pierre Hugot, Gauthier Dobigny

\section{To cite this version:}

Daleen Badenhorst, Vincent Herbreteau, Yannick Chaval, Marie Pages, Terence J. Robinson, et al.. New karyotypic data for Asian rodents (Rodentia, Muridae) with the first report of B-chromosomes in the genus Mus.. Journal of Zoology, 2009, 279 (1), pp.44-56. 10.1111/j.1469-7998.2009.00588.x . hal-00545596

\section{HAL Id: hal-00545596 \\ https://hal.science/hal-00545596}

Submitted on 15 May 2020

HAL is a multi-disciplinary open access archive for the deposit and dissemination of scientific research documents, whether they are published or not. The documents may come from teaching and research institutions in France or abroad, or from public or private research centers.
L'archive ouverte pluridisciplinaire HAL, est destinée au dépôt et à la diffusion de documents scientifiques de niveau recherche, publiés ou non, émanant des établissements d'enseignement et de recherche français ou étrangers, des laboratoires publics ou privés. 


\section{New karyotypic data for Asian rodents (Rodentia, Muridae)} with the first report of B-chromosomes in the genus $M u s$

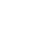

Daleen Badenhorst ${ }^{1}$, Vincent Herbreteau $^{2}$, Yannick Chaval $^{3}$, Marie Pages ${ }^{3}$,

Terence J. Robinson ${ }^{1}$, Worawut Rerkamnuaychoke ${ }^{4}$, Serge Morand ${ }^{5}$, Jean-Pierre

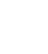
$\operatorname{Hugot}^{6} \&$ Gauthier Dobigny ${ }^{3 *}$

\section{(1)}

${ }^{1}$ Evolutionary Genomics Group, University of Stellenbosch, Botany and Zoology

Department, Private Bag X1, 7604 Matieland, South Africa.

${ }^{2}$ Territoires, Environnement, Télédétection et Information Spatiale (UMR TETIS

Cemagref-CIRAD-AgroParisTech) Maison de la Télédétection, 500 rue JF Breton, 34093

Montpellier Cedex 5, France.

${ }^{3}$ Centre de Biologie pour la Gestion des Populations (UMR 022 INRA-IRD-CIRAD-

SupAgro), Campus de Baillarguet, CS30016, 34988 Montferrier-sur-Lez, France.

${ }^{4}$ College of Veterinary Technology, Kasetsart University, 50 Paholyothin Rd, 10900 Bangkok, Thailand.

${ }^{5}$ Institut des Sciences de l'Evolution (UMR 5554 CNRS-IRD-UM2), Université de Montpellier II, Bâtiment 22, Place E. Bataillon, 34095 Montpellier, France.

${ }^{6}$ Laboratoire Origine, Structure et Evolution de la Biodiversité (UMR 5202 CNRS-MNHN), Muséum National d'Histoire Naturelle, 55 rue Buffon, 75005 Paris, France

* Corresponding author: Gauthier.Dobigny@ird.fr

Keywords: cytotaxonomy - systematics - sibling species - Rattini

Running title: Cytotaxonomy in Asian Rodents 


\section{Abstract (216 words)}

Karyotypes of 18 rodent species collected in various localities in Thailand were analysed as part of an epidemiological survey of the region using conventional cytogenetic techniques. The aim was to re-assess the reliability of karyotype-based diagnoses of Thai rodents using an updated taxonomic framework. Species examined include Menetes berdmorei (Sciuridae), Mus caroli, M. cervicolor and M. cookii, Hapalomys delacouri, Chiropodomys gliroides, as well as several representatives of most of the lineages of the Rattini tribe i.e. Rattus exulans, R. losea, R. tanezumi, Leopoldamys edwardsi, L. neilli, Maxomys surifer, Niviventer fulvescens, Berylmys berdmorei, B. bowersi, Bandicota indica and B. savilei (Muridae). The first descriptions of G- and/or C-banding karyotypes are provided for several of these i.e., $B$. savilei, L. edwardsi, M. surifer, B. berdmorei, B. bowersi, N. fulvescens and H. delacouri. Although largely in agreement with available data, our findings on chromosomes morphology differ slightly from those published for L. edwardsi, M. surifer, B. savilei, and the two Berylmys species, B. berdmorei, and B. bowersi. In addition, we document the novel finding of B-chromosomes in the genera Berylmys, Bandicota and the emblematic Mus. Importantly, few species-specific chromosomal characters could be identified within most of the genera investigated in our study and, contrary to previous claims, the usefulness of karyotypes for diagnosing these Asian murid species appears limited. 


\section{INTRODUCTION}

(1)

The non-ambiguous identification of species is critical for fundamental as well as applied research, as it is the departure point for many aspects of comparative biology including systematics (e.g., Sites \& Marshall, 2003, and references therein), biodiversity assessments, conservation (Crandall et al., 2000; Moritz, 2000), biogeography (e.g., Avise 2009), community ecology and pests control (e.g., Hoffman, 2002). In particular, the lack of accurate species-specific identification of hosts is an important consideration for current epidemiological surveys since 1) numerous pathogens are carried by a restricted range of hosts, and 2) each rodent species possesses its own life traits. These two aspects are pivotal since they may lead to important differences in the role a host species can play in circulation and transmission of pathogens. For instance, a species may be an important reservoir for a human pathogen while its close, and sometimes morphologically similar relatives, are not (e.g., the two cryptic species Mastomys natalensis and M. erythroleucus, and their association with the Lassa Fever arenavirus in Africa; Lecompte et al., 2006). Additionally, some species-specific ecological characteristics (such as commensality and hence the propensity to transport with humans) and evolutionary properties (population structure and connectivity) are also central to epidemiological processes (reviewed in Mills \& Childs, 1998). In such a context, karyotypic data has been shown to be valuable, especially for identifying rodents that belong to sibling species complexes.

We carried out a survey of various rodent species found in different localities in Thailand as part of an epidemiological survey in this region. In particular, we focused on murids (rats and mice) that are suspected of being important reservoirs for several human pathogens (i.e., those responsible for hantavirus-mediated hemorrhagic fevers, typhus, leptospirosis, among others). 
The first goal was to develop identification "tools" for use at the species-level. That this approach has application is illustrated by the Asian Hantaviruses (responsible for lethal haemorrhagic fevers) / rodents association found in Cambodian Rattus specimens that could not be discriminated at the species level (Reynes et al., 2003).

Asia is the area of origin for the Rattus sensu lato complex (i.e., Rattus sensu stricto and allied genera), a complex that includes the biological important index species, $R$. norvegicus (Aplin et al., 2003). Surprisingly, given their epidemiological importance, karyotypic data on species in this complex are limited. Even more importantly, numerous systematic modifications (reviewed in Wilson \& Reeder, 2005) have been proposed since the pioneering cytotaxonomic work published in the late 1960s to the 1970s (see Marshall, 1977, and references therein), further complicating interpretations of correspondence between karyotype and host species. For example, many (if not most) of the taxa that were originally considered as different $R$. rattus subspecies (e.g., tanezumi, argentiventer, rattus) are now regarded as synonyms or have been elevated to distinct species. In the same manner, many congeneric species have been split into different genera (e.g., Berylmys, Maxomys, Leopoldamys, Niviventer). Consequently, species-specific karyotypes are often difficult to delimit, thus making a cytotaxonomic approach to species identification problematic.

In an attempt at redress, we performed a conventional cytogenetic analysis of 18 rodent species: Menetes berdmorei (Sciuridae), Mus caroli, M. cervicolor and M. cookii, Chiropodomys gliroides, Hapalomys delacouri, as well as representatives of most of the lineages within the Rattini tribe (sensu Lecompte et al., 2008), i.e. Rattus exulans, R. losea, $R$. tanezumi, Leopoldamys edwardsi, L. neilli, Maxomys surifer, Niviventer cf. langbianis, 
114 The majority of chromosome preparations were done in the field using the air-drying method 115 on femoral bone marrow following yeast stimulation (Evans et al., 1963; Lee \& Elder, 1980). In eleven instances (Tab. 1), intercostal tissue was sampled to establish fibroblast cell cultures

117 using conventional techniques. Freshly prepared hypotonic $(0.75 \mathrm{M} \mathrm{KCl})$ and fixative (acetic 118

Berylmys berdmorei, B. bowersi, Bandicota indica, B. savilei. Our aim was to re-assess the reliability of karyotype-based diagnoses of Thai rodents, in an updated taxonomic framework.

\section{MATERIAL and METHODS}

Thousands of rodents have been trapped and are currently under investigation as part of a long-term epidemiological survey of rodent-borne pathogens in South Eastern Asia. Among these, sixty five specimens were collected in 2006 and 2007 in Northern and North-Eastern Thailand in the vicinity of the settlements Loei $\left(17^{\circ} 29 \mathrm{~N} 101^{\circ} 43 \mathrm{E}\right)$, Phrae $\left(18^{\circ} 09 \mathrm{~N} 100^{\circ} 08 \mathrm{E}\right)$ and Kalasin $\left(16^{\circ} 26 \mathrm{~N} 103^{\circ} 31 \mathrm{E}\right)$ using locally made locally made cage-traps. Except where otherwise detailed, taxonomy follows Carleton \& Musser (2005). Species identifications were based on external measurements, morphological features, and, in females, mammae formula (Marshall, 1977; Corbet \& Hill, 1992; Aplin et al., 2003). Moreover, taking into account the ambiguous status of some of these diagnostic characters, most of the murine specimens were also investigated using molecular analyses (Tab. 1) involving several mitochondrial (cytochrome b, CO1, and 16S rDNA) and nuclear (IRBP) gene fragments. The DNA-based analyses will be presented elsewhere as a separate phylogenetic study (Pagès et al., in prep.). Importantly, however, and pivotal to the present work, our species-specific identifications relied on correspondence in both morphological and molecular data. acid-methanol 1:3) solutions were routinely used. Cell suspensions were stored in fixative and 
119 transported to the laboratory where conventional staining, G- and C-banding (Seabright 1971;

120 Sumner 1972) and image capture using the Genus software (Applied Imaging), were

121 performed. A minimum of five complete metaphases were analysed for each specimen.

122 Diploid (2n), fundamental (NF; i.e., total numbers of chromosomal arms in one cell) and

123 autosomal fundamental (NFa; i.e., NF excluding sex chromosomes) numbers were

124 determined, and karyotypes were arranged according to chromosomes morphology and size

125 (conventional staining) and/or banding patterns. Chromosome nomenclature for Rattus 126 followed Yosida $(1976,1977 a)$.

\section{RESULTS and DISCUSSION}

130 All specimens were analyzed using conventional staining, thus allowing an overall description

131 of the species-specific karyotypes (Tab. 1). In addition, G-banded karyotypes were

132 constructed where feasible. However, in several instances, slight variation and/or ambiguities

133 in NF/NFa values were detected through conventional staining (Giemsa only) reflecting the

134 difficulty in categorizing acrocentric/subtelocentric chromosomes where chromosomal

135 contraction can be a confounding factor. Although not uncommon in mammalian 136 cytogenetics, subtle differences in chromosome morphology (such as telocentric vs.

137 subtelocentric) has been considered important in murine cytotaxonomy where it has been used 138 to underpin the species identification of several taxa (e.g., Marshall, 1977, p. 407-408). In an 139 attempt to constrain ambiguities introduced by terminology, we have chosen to view all

140 chromosomes that have no visible short arm as telocentric and those that possess minute arms 141 as acrocentric elements (subtelocentric chromosomes in some schemes) for $\mathrm{NF} / \mathrm{NFa}$ 142 assessment. If the short arms were more pronounced and clearly and repeatedly observed, 143 chromosomes were considered to be as bi-armed (submetacentric and metacentric). 
Menetes berdmorei (Blyth, 1849) (Sciuridae)

146

147 The only squirrel (which is a sciurid, not a murid rodent) investigated in this study had a

$1482 \mathrm{n}=38$ chromosome number. Most of the chromosomes were metacentric or submetacentric

149 except for the five smallest pairs that were either telocentric or acrocentric $(\mathrm{NF}=76, \mathrm{NFa}=72)$.

150 This is in agreement with data previously published by Viegas-Péquignot et al. (1986) and

151 Richard et al. (2003) on this species, and also specimens analysed by Marshall (1977) from

152 Thailand. As a result the karyotype is not repeated here.

Rattus exulans (Peale, 1848), R. losea (Swinhoe, 1871) and R. tanezumi (Temmink, 1844)

155

In total 26 specimens of Rattus sensu stricto were karyotyped (Tab. 1; data not shown). These included $R$. losea $(\mathrm{n}=5), R$. tanezumi $(\mathrm{n}=13)$ and $R$. exulans $(\mathrm{n}=8)$. All but one specimen were determined to have a diploid number of 42 with NF values ranging from 56-61, 58-60 and 54-

59 in $R$. exulans, $R$. losea and $R$. tanezumi, respectively. The $2 \mathrm{n}=43$ R. tanezumi specimen

160 was characterized by the presence of a G-negative and C-positive B-chromosome (data not 161 shown), as has previously been documented in this taxon (Yosida, 1976, 1977b; Gadi \&

162 Sharma, 1983). The largely overlapping NF values are attributable to variation in the short 163 arms ( $\mathrm{p}$ arms) of several pairs resulting in their classification as acrocentric and/or

164 submetacentric homologs (see Table 2). The polymorphisms most likely correspond to 165 variation in pairs 1,9 and 13 of Rattus $r$. tanezumi (now named $R$. tanezumi; see Wilson \& 166 Reeder, 2005) sensu Yosida and colleagues (1971a, 1971b, 1976 and 1977a). This variation in 167 centromere position has been noted in several Rattus species and subspecies (Yosida et al., 168 1971a, 1971b, 1974; Yosida, 1973, 1977a; Yosida \& Sagai, 1973, 1975; Gadi \& Sharma, 
169 1983; Motokawa et al., 2001) and is interpreted to result from pericentric inversion (Yosida $e t$ 170 al., 1971a, 1971b; Yosida, 1976, 1977a) and/or heterochromatin amplification/deletion

171 (Yosida \& Sagai, 1975; Baskevich \& Kuznetsov, 1998). However, the chromosomes and/or

172 the segments involved are small and thus difficult to interpret, even when using G-banding,

173 and the mechanism(s) underpinning this variation remains moot.

175 Importantly, Marshall (1977) proposed a number of apparently fixed (diagnostic) features 176 among $R$. exulans, $R$. losea and $R$. tanezumi (which is synonymous with $R$. $r$. thai sensu 177 Marshall; see Wilson \& Reeder, 2005) in Thailand. On the basis of conventional staining, 178 Marshall argues (pp. 407-408) that: i) pair 1 is acrocentric in $R$. tanezumi and submetacentric 179 in $R$. exulans and $R$. losea, ii) pair 9 is submetacentric in $R$. losea but acrocentric in $R$. exulans 180 and $R$. tanezumi, and iii) pair 11 (most probably corresponding to pair 13 sensu Yosida et al.) 181 is submetacentric in $R$. exulans, whereas it is acrocentric in $R$. losea and $R$. tanezumi.

182 However, taking other studies into account (see above) and our own data (Table 2), it appears 183 that none of these chromosomal morphs (1,9 or 13) can be considered as species-specific. 184 Moreover, heterozygotes for each of these three pairs were found in $R$. exulans and $R$. 185 tanezumi (our study, Tab. 2), suggesting that these chromosomal polymorphisms were present 186 in their last common ancestor and are therefore ancestral to the Rattus sensu stricto clade 187 (Yosida et al., 1971a, 1971b; Yosida \& Sagai, 1975, Yosida, 1977) and date back 2.2 My 188 (Robins et al., 2008).

190 Leopoldamys edwardsi (Thomas, 1882) and L. neilli (Marshall Jr, 1976)

192 The five L. edwardsi specimens investigated in this study all display identical karyotypes 193 (Fig. 1) with $2 \mathrm{n}=42$ chromosomes. Most of the autosomes are acrocentric, except for four of 
194 the five largest autosomal pairs (pairs 1, 2, 3 and 5 in Fig. 1) which possess short arms, as 195 well as the three smallest ones which are metacentric (pairs 18, 19 and 20). The $\mathrm{X}$ is a 196 medium size acrocentric chromosome, whereas the $\mathrm{Y}$ is C-positive and dot-like (and most

197 likely acrocentric) element $(\mathrm{NFa}=54)$. Clearly observable blocks of C-positive 198 heterochromatin were detected in several pericentromeric and telomeric regions, as well as in 199 an intercalary position on one of the largest pairs (Fig. 1b; pair 2 on Fig. 1a).

201 Although L. edwardsi (from an unknown locality) was recently proposed to have $2 \mathrm{n}=44$ chromosomes (Sablina et al., unpubl., quoted in the "Atlas of Mammalian Chromosomes", ed. S.J. O'Brien et al., 2007), our karyotypic results are in agreement with other reports (Yong, 1970; Rickart \& Musser, 1993, and references therein). However, there is also a difference in the morphology of the Y chromosomes: the Y identified by Yong (1970) is a normal sized acrocentric, while our Y clearly appears as a dot like element (Fig 1b), suggesting there may be more fundamental differences underlying these observations.

A single Leopoldamys female trapped in the vicinity of limestone karsts was referred to as $L$.

210 neilli on the basis of morphology as well as unambiguous molecular results (Pagès et al., in

211 prep.). Even though our preparation was of poor quality (data not shown), making G-banding analysis problematic, the specimen unambiguously displayed $2 n=44$ chromosomes, with two

213 large submetacentric and two small metacentric pairs $(\mathrm{NF}=52)$. These findings are in good 214 agreement with previous reports $(\mathrm{NF}=52$ in Marshall, 1977) but differ from the $\mathrm{NF}=50$ noted 215 by Rickart \& Musser (1983).

217 It would appear, therefore, that the two Leopoldamys species can be distinguished by 218 karyotypes: $L$. edwardsi with $2 \mathrm{n}=42 / \mathrm{NF}=56$ and $L$. neilli with $2 \mathrm{n}=44 / \mathrm{NF}=52$. A third species, 
219 L. sabanus, which is morphologically similar to L. edwardsi, has also been described from 220 Thailand (Wilson \& Reeder, 2005). The L. sabanus karyotype differs slightly from that of $L$. 221 edwardsi since Marshall (1977) recorded a $2 \mathrm{n}=42 / \mathrm{NF}=54$ complement for this species.

222 Unfortunately, no material was available to us to address the delimitation of the L. edwardsi / 223 L. sabanus species. However, we anticipate that karyotypic differences between these two 224 taxa are subtle, therefore unreliable for diagnostic purposes.

\section{Niviventer fulvescens}

Taxonomy within Niviventer is in need of revision (Wilson \& Reeder, 2005). The results of our preliminary molecular (Pagès et al., in prep.) and morphological (Chaval, unpubl.) investigations are concordant and show that the three specimens analysed karyotypically by us form a natural grouping and are referred to herein as $N$. fulvescens (Pagès et al., in prep.).

Of these three specimens, a male was used to establish a fibroblast culture but the resulting lines appear to have undergone de novo rearrangement in culture. Nonetheless, the rearranged

234 karyotype corresponds relatively well to the bone marrow karyotypes of the other two specimens which were both characterized by $2 \mathrm{n}=46$ (NFa=52; Fig. 2). All chromosomes are acrocentric except for the submetacentric pair 2, as well as the three of the shortest autosomal pairs which are metacentric. The $\mathrm{X}$ is a large acrocentric chromosome, and the $\mathrm{Y}$ is a tiny acrocentric element which is entirely C-positive (data not shown). As far as we know, the G239 banding karyotype of $N$. fulvescens (Fig. 2) is presented here for the first time.

There are few published karyotype reports on subspecies/species of Niviventer and these are

242 limited to using conventional staining, the only exception being Wang et al. (2003) on $N$. confucianus. Except for tiny differences in centromeric placement, N. rapit, N. bukit, N. 
hinpoon (Yong, 1969; Markvong et al., 1973; Marshall, 1977), N. langbianis (Baskevich \&

Kuznetsov, 2000), N. fulvescens (Duncan et al., 1970, 1974) and N. cremoriventer (Yong, 1969) are all invariant and closely resemble the cytotype that we present here for $N$. fulvescens. It is important to note that $N$. rapit and $N$. bukit from Thailand have since then 248 been collapsed into N. fulvescens (see Musser, 1981; Abe, 1983). The cytogenetic criteria 249 proposed to discriminate all these Niviventer species are based on subtle shape differences of 250 some pairs (see Table 2 in Wang et al., 2003) which are most probably due to variation in heterochromatin, as observed between $N$. tenaster, $N$. fulvescens and $N$. langbianis (all from Vietnam) following C-banding protocols (Baskevich \& Kuznetsov, 2000). Although we cannot state with certainty, it is highly probable that karyotypic variations within the genus will be too obscure to provide reliable cytotaxonomic identification.

Maxomys surifer (Miller, 1900)

Five males and one female of $M$. surifer were analysed and the G-banded karyotype is 259 presented for the first time (Fig. 3). All specimens displayed 2n=52, with seven metacentric 260 (pairs 4, 5 and 14 in Fig. 3) or submetacentric (pairs 10, 12, 18 and 24) chromosomal pairs 261 (NF=66). The Y chromosome is the smallest element, is entirely heterochromatic (Fig. 3b), 262 and appears acrocentric in morphology. This is in agreement with available data for M. surifer 263 from South East Asia (see Rickart \& Musser, 1993, and references therein) including 264 Thailand (Marshall, 1977). However, some differences exist between these studies and the 265 results of the present report especially with respect to the identification of the X chromosome. The $\mathrm{X}$ was described as a metacentric in specimens collected from localities in Thailand 267 (Marshall, 1977), Vietnam and Malaysia (see Rickart \& Musser, 1993, and references 268 therein), resulting in $2 \mathrm{n}=52 / \mathrm{NFa}=62$. In sharp contrast, the $\mathrm{X}$ chromosome is one of the 

chromosomes in this genus.

largest chromosomal elements in specimens analysed by us, and is clearly acrocentric. ZooFISH analysis using a $R$. norvegicus X painting probe (Badenhorst et al., unpubl.) allowed us to confirm this result. Our $M$. surifer specimens are consequently characterized by $\mathrm{NFa}=64$, and not $\mathrm{NFa}=62$. When one considers our findings on the morphology of the $\mathrm{X}$ chromosome, the difference in $\mathrm{NFa}(\mathrm{NFa}=62$ vs 64) may be due to (i) a misidentification of the $\mathrm{X}$ in the past, (ii) a polymorphism that would involve the $\mathrm{X}$ chromosome, or (iii) the co-existence of different but cryptic Maxomys species that differ in the morphology of the X chromosome. Further sampling and karyotyping will be required to address this point.

Berylmys berdmorei (Anderson, 1879) and B. bowersi (Blyth, 1851)

A single $B$. berdmorei female, as well as one male and one female of $B$. bowersi were karyotyped. All three specimens had $2 \mathrm{n}=40$. The karyotype comprised two large (pairs 1 and 2 in Fig. 4 and 5), four medium-size (pairs 5, 6, 9 and 11) and one small submetacentric pairs (pair 18), one large (pair 3), five medium-size (pairs 12-16) and one small metacentric pair (pair 17), and three medium-size (pairs 4, 7, 8 and 10) and one short acrocentric (pair 19) pairs of chromosomes $(\mathrm{NFa}=64$; see Fig. 4 and 5). The $\mathrm{X}$ is a medium-size acrocentric chromosome and the $B$. bowersi $\mathrm{Y}$ is a small acrocentric element. Our results are in good agreement with previous reports (reviewed in Marshall and Newcomb, 1983) that suggested $2 \mathrm{n}=40$ and $\mathrm{NFa}=64$ for both species. An additional female $B$. berdmorei specimen was found to have $2 n=41$ due to the presence of an extra C-negative metacentric element that did not match with any of the other elements of the karyotype using G-banding comparison (Fig. 4) suggesting that this may be a B-chromosome. To our knowledge, this is the first report of B- 
294 Our results show some differences to those of Yong (1968) and Yosida (1973) who identified 295 six pairs of acrocentric, eight pairs of metacentric and five pairs of subtelocentric autosomes;

296 they also show a medium sized acrocentric $\mathrm{X}$ chromosome and a small acrocentric $\mathrm{Y}$ in

297 specimens of $B$. bowersi. This mirrors other conflicting reports regarding the $B$. berdmorei 298 karyotype. Marshall (1977) described six telocentric, six subtelocentric and seven metacentric 299 pairs of autosomes in B. bowersi from Thailand, whereas Yong (1968) recorded eight pairs of 300 metacentrics, nine pairs of subtelocentrics, two pairs of acrocentric autosomes and a medium 301 sized subtelocentric X in specimens from Malaysia. Conversely, Markvong et al. (1973) and 302 Duncan et al. (1970) identified five pairs of subtelocentrics, eight pairs of metacentrics and 303 six pairs of acrocentrics in this species in Thailand and Vietnam. The $\mathrm{X}$ and $\mathrm{Y}$ chromosomes 304 of $B$. bowersi described by Yong (1968) and Yosida (1973) are comparable to our own. 305 Conversely the B. berdmorei X has previously been reported as subtelocentric (Yong, 1968), 306 while our specimens clearly possessed an acrocentric X, in agreement with both Duncan et al. 307 (1970) and Markvong et al. (1973). Furthermore, we were unable to retrieve the two species308 specific differences that were proposed to differentiate the karyotypes, i.e. a subtelocentric vs.

309 acrocentric pair 6 , and an acrocentric vs. subtelocentric pair 11 in $B$. berdmorei and $B$. 310 bowersi, respectively (see Marshall, 1977). Given that our C-banding data show the presence 311 of several C-positive short arms (Fig. 4 and 5) which may be responsible for variations in 312 chromosome morphology (i.e., the interpretation of acrocentric vs. subtelocentric), it seems 313 prudent to conclude that the two Berylmys species cannot be distinguished cytogenetically 314 with any confidence. 
318 Eight bandicoot-rats, including two B. indica (one male, one female) and six B. savilei (four males, two females) specimens were karyotyped.

321 The $B$. indica specimens were characterized by $2 \mathrm{n}=44$ and 45 , respectively (data not shown).

322 Unfortunately, well resolved G- and C-banded chromosomes could not be produced due to the 323 poor quality of our preparations. That said, the $2 n=45$ male clearly possessed 26 bi-armed 324 chromosomes $(\mathrm{NF}=71)$ including a moderately large submetacentric $\mathrm{X}$. The rest of the 325 karyotype was composed of acrocentric elements, most probably including the Y (which 326 would result in $\mathrm{NFa}=68$ ) although its unambiguous identification was not possible from our 327 preparations. The $2 \mathrm{n}=44$ female was characterized by the same karyotypic morphology, 328 except that it possessed one more acrocentric but one less bi-armed chromosome (data not 329 shown). Although the difference between the $2 n=44$ and $2 n=45$ karyotypes may suggest a 330 Robertsonian polymorphism in $B$. indica, based on our data we are unable to reach a 331 definitive conclusion. Consequently, other explanations (e.g., X-autosome translocations, B 332 chromosomes) cannot be excluded at this stage. For example, $B$. indica has been previously 333 reported to contain 1-3 B chromosomes (Gadi et al., 1982; Gadi \& Sharma, 1983).

334 Importantly, however, our results are slightly different to those previously published for this 335 species collected from Thailand (2n=46; Markvong et al., 1973; Marshall, 1977), but are 336 consistent with data on specimens from India $(2 \mathrm{n}=42$ for $B$. indica indica, and $2 \mathrm{n}=44$ for $B$. 337 indica nemorivaga; Ranjini, 1967; Avirachan et al., 1971; Gadi and Raman, 1977; Gadi \& 338 Sharma, 1983). When taken together, the variation in $2 \mathrm{n}$ suggests a more complex systematic 339 situation than currently thought within $B$. indica, and/or that there is a chromosomal 340 polymorphism that remains to be described. 
342 Three males and two females of $B$. savilei were characterised by $2 n=43$ (Fig. 6). The diploid 343 number of an additional male specimen was determined to be $2 \mathrm{n}=45$. Unfortunately, as for $B$.

344 indica, our preparations were of very poor quality thus greatly limiting the description of

345 these karyotypes and our interpretation of their differences. The fundamental number could 346 not be determined confidently from these five specimens. Nevertheless, we were able to 347 establish a cell line for one female allowing for a more detailed investigation of the $B$. savilei 348 karyotype. This specimen had $2 \mathrm{n}=43$ comprising 23 meta- and submetacentric elements 349 (NF=64; Fig. 6). Among the bi-armed chromosomes two correspond to the large metacentric $\mathrm{X}$ pair (as confirmed by Zoo-FISH using a Rattus norvegicus X paint; Badenhorst et al., 351 unpubl.), and one was a B chromosome (Fig. 6a). C-banding showed that the $\mathrm{X}$ long arms as 352 well as several acrocentric and metacentric centromeric regions were C-positive (Fig. 6b). 353 More surprisingly, the B-chromosome did not appear strongly stained following C-band (Fig. 6b). We are not aware of previous reports of B-chromosomes in B. savilei.

356 The karyotype described above differs from previous reports for specimens of this species 357 collected in Thailand $(2 \mathrm{n}=44, \mathrm{NFa}=58$; Markvong et al., 1973). Markvong et al., (1973) 358 described a karyotype consisting of six pairs of small metacentrics and two pairs of 359 subtelocentrics and thirteen pairs of acrocentrics. Also, the largest autosomal pair was clearly 360 submetacentric. Furthermore, the $\mathrm{X}$ of $B$. savilei was previously identified as a medium-sized 361 acrocentric which differentiates it from other lesser bandicoot rats (Markvong et al., 1973; 362 Gadi \& Sharma, 1983). In absence of comparable data, we are unable to explain such 363 differences. However, in our specimen the $\mathrm{X}$ was identified unambiguously by Zoo-FISH 364 analysis (Badenhorst et al., unpubl.) as a large submetacentric chromosome. Therefore, males 365 of $B$. savilei should have a $2 \mathrm{n}=43+1 \mathrm{~B}$ karyotype (i.e., XY1Y2 males). Clearly, this requires 366 confirmation by further cytogenetic investigations. 
Hapalomys delacouri Thomas, 1927

370 A fibroblast cell culture was established from a male $H$. delacouri specimen caught in the

371 vicinity of Loei, and our data are the first for this species from Thailand. Its karyotype was 372 characterized by $2 \mathrm{n}=48$ chromosomes and an $\mathrm{NFa}=92$ (Fig. 7). All the autosomes were bi373 armed (metacentric or submetacentric). The metacentric $\mathrm{X}$ and the acrocentric $\mathrm{Y}$ were easily 374 recognizable since they were respectively the largest and the smallest elements in the 375 karyotype. Our findings differ significantly from published data on $H$. longicaudatus (Yong et 376 al., 1982) in that these authors describe specimens from Malaysia as having $2 \mathrm{n}=50$, with the

$377 \mathrm{X}$ and $\mathrm{Y}$ chromosomes having similar morphology; all the autosomes were reported as 378 acrocentric. This suggests that cytotaxonomy may be a valuable diagnostic tool within the 379 genus. Our results constitute the first karyotypic data for this very poorly documented species. 380 Interestingly, two classes of C-positive material were identified on staining intensity 381 suggesting a different repeat composition for this heterochromatic material (Fig. 7b). The 382 genome appears to be particularly rich in heterochromatin, with some chromosome pairs 383 displaying entirely heterochromatic long arms.

Chiropodomys gliroides (Blyth, 1856)

387 A fibroblast cell culture was established from a male $C$. gliroides specimen that possessed an 388 entirely acrocentric chromosomal complement $(2 n=42, N F=42)$, including the $X$ and $Y$ 389 chromosomes $(\mathrm{NFa}=40)$. Unfortunately, the preparations were of poor quality and 390 construction of a G-banded karyotype was not possible. Nevertheless, strongly positive C391 bands could be clearly observed in all pericentromeric regions, whereas the Y chromosome 
392

393

394

395

396

was entirely heterochromatic, although less heteropycnotic that the pericentromeric material of the autosomes (Fig. 8). These results are in partial agreement with previous data concerning this very poorly documented species. Yong $(1973$, 1983) reported that eight Malayan specimens were characterized by $2 n=42$ with most chromosomes being acrocentric in morphology with C-positive pericentromeric regions (Yong, 1983). Additionally there was one metacentric chromosome pair, a submetacentric chromosome pair, and the sex chromosomes were bi-armed. These bi-armed elements were all clearly absent in our single specimen of this species (Fig. 8). At this point, we cannot distinguish whether the differences are intraspecific (i.e. represent polymorphisms), or that they underpin the recognition of apparently cryptic species within $C$. gliroides.

Mus caroli (Bonhote, 1902), M. cervicolor Hodgson, 1845 and M. cookii Ryley, 1914

Seven male and seven female mice, trapped close to or within pineapple fields in Loei, were characterized by an identical $2 \mathrm{n}=40$ acrocentric karyotype $(\mathrm{NFa}=38)$. The karyotypes of the Thailand species M. musculus castaneus, M. caroli, M. cervicolor, M. cookii, M. shortridgei and M. fragilicauda (see Auffray et al., 2003, and references therein) all have the same invariant karyotype (Auffray et al., 2003) indistinguishable from that evidenced by our specimens. Molecular typing using rDNA16S and rDNA28S nucleotide sequences of the 14 specimens analysed by us allowed the identification of three different species in our sample, M. caroli, M. cervicolor and M. cookii (A. Orth, pers. comm.). Several of these animals were caught in the same trap lines, often only meters apart, thus representing another report of true syntopy as has been similarly suggested for M. caroli, M. cervicolor and M. fragilicauda in Thailand (Auffray et al., 2003). 
417 In addition, two female specimens, identified as M. cookii on nucleotide sequences (A. Orth, 418 pers. comm.), had $2 \mathrm{n}=41$ chromosomes (Fig. 8). The two karyotypes each comprised 40

419 acrocentric chromosomes, in addition to one unpaired medium-size metacentric and one

420 unpaired acrocentric element respectively. These two unpaired chromosomes are G-negative

421 (not shown) and C-positive (Fig. 8b) and are considered by us to be B-chromosomes. To our

422 knowledge, this is the first report of B-chromosomes in the genus Mus. Although several 423 hypotheses have been proposed to explain some aspects of the biology of these extra, non424 Mendelian chromosomes (reviewed in Camacho et al., 2000), little is known about their 425 origin and their impact on the genomes, especially in mammals. Keeping in mind the 426 importance of the mouse as a biological model, this observation clearly merits further 427 investigation.

Conclusion: chromosomal evolution in Thai rodents and epidemiological implications

Despite a central role as reservoirs and/or vectors of several human diseases, reliable

432 systematic data necessary to underpin accurate species-specific geographical, ecological and genetic information on Asian rodents are limited, and many taxonomic associations are unclear. Cytotaxonomy has been of great help in similar epidemiological investigations on other continents i.e., Africa), frequently providing unambiguous identification of species

436 including those that are morphologically cryptic (e.g., Duplantier et al., 1990; Volobouev et 437 al., 2002; Dobigny et al., 2003; Granjon \& Dobigny, 2003; Rambau et al., 2003; Veyrunes et 438 al., 2004). However, apart from Hapalomys, the preliminary results presented here suggest 439 that this does not hold for the Asian species surveyed in our study. Although most genera can 440 routinely be discriminated on karyotype (as they often can on morphology), few species441 specific chromosomal characters could be identified within genera investigated herein. For 
442 instance, although $L$. neilli and L. edwardsi could be delimited cytogenetically, the two

443 Berylmys, three Mus, three Rattus species analysed by us are indistinguishable on karyotype.

444 Although it remains to be confirmed, a similar situation may exist within Niviventer, as well

445 as between L. edwardsi and L. sabanus. Karyotypic criteria that have previously been claimed

446 to be diagnostic appear in our analyses to simply represent ancestral polymorphisms that are

447 still undergoing idiosyncratic lineage sorting (i.e., hemiplasic characters sensu Avise \& 448 Robinson, 2008; Robinson et al., 2008), thus impacting on the usefulness of these as 449 diagnostic markers in species identification. Our findings suggest that new diagnostic features 450 should be sought as a matter of urgency for use in these epidemiologically important rodent 451 groups. DNA-based methods such as primer-specific analysis that have been used 452 successfully in Africa (e.g., Lecompte et al., 2005) and Europe (e.g., Michaux et al., 2001) 453 are compelling candidates that should be prioritised for testing in Asian murids.

\section{Acknowledgements}

457 This study is part of the « Biodiversité Comparée des Roboviroses à Hantavirus en Europe et en Asie du sud-est » programme (ANR Project n00121-05, J.P. Hugot). Daleen Badenhorst research is supported by a NRF bursary and a bilateral France/South Africa Protea grant to GD and TJR. We are grateful to Annie Orth and Josette Catalan for their help in the lab, Jo and Kaï (drivers), Kittiponk Chaisiri, Khomson Satchasataporn, the staff and students from

462 the Faculty of Veterinary Technology, Kasetsart University, as well as the villagers in Loei 463 and Phrae for their help in preparing and assisting the fieldwork. Cell culture experiments were performed using facilities provided by the "Evolutionary consequences of inversion polymorphism in Mammals" programme (ANR Project n ANR05-JC05-48631, G. Dobigny) and the Evolutionary Genomics Group, University of Stellenbosch. 


\section{Bibliography}

468

469 Aplin, K., Chesser, T. \& Ten Have, J. (2003). Evolutionary biology of the genus Rattus:

470 profile of an archetypal rodent pest. In Rats, mice and people: rodent biology and 471 management: 487-498. (Eds). Singleton, G.R., Hinds, L.A., Krebs, C.J. \& Spratt DM: 472 ACIAR Canberra, Australia.

473 Aplin, K.P., Brown, P.R., Jacob, J., Krebs, C.J. \& Singleton, G.R. (2003). Field methods for 474 rodent studies in Asia and the Indo-Pacific. ACIAR Monograph 100.

475 Auffray, J.C., Orth, A., Catalan, J., Gonzalez, J.P., Desmarais, E. \& Bonhomme, F. (2003). 476 Phylogenetic position and description of a new species of subgenus Mus (Rodentia, 477 Mammalia) from Thailand. Zool. Scr. 32, 119-127.

478 Avise, J.C. (2009). Phylogeography: retrospect and prospect. J. Biogeogr. 36: 3-15

479 Avise, J.C. \& Robinson, T.J. (2008). Hemiplasy: a new term in the lexicon of phylogenetics. $480 \quad$ Syst. Biol. 57, 503-507.

481 Baskevitch, M.I. \& Kuznetsov, G.V. (2000). Preliminary chromosomal results of Niviventer 482 Marshall, 1976 (Mammalia, Rodentia, Muridae) from the Dalat plateau in Southern 483 Vietnam. In Isolated Vertebrate Communities in the Tropics: 351-356. (Eds). Rheinwald, G.: Proc. $4^{\text {th }}$ Int. Symp. Bonn, Bonn zool. Monogr. 46.

Camacho, J.P.M., Sharbel, T.F. \& Beukeboom, L.W. (2000). B-chromosome evolution. Phil. Trans. Roy. Soc. Lond. B 355, 163-178.

487 Corbet, G.B. \& Hill, J.E. (1992). Mammals of the Indomalayan Region: a systematic review. 488 Natural History Museum Publications and Oxford University Press, London and Oxford, $489 \quad$ U.K., 488p.

490 Crandall, K.A., Bininda-Emonds, O.R.P., Mace, G.M. \& Wayne, R.K. (2000). Considering 491 evolutionary processes in conservation biology. Tr. Ecol. Evol. 115, 290-295. 
Dobigny, G., Nomao, A. \& Gautun, J.C. (2002). A cytotaxonomic survey of Rodents from Niger: implications for systematics, biodiversity and biogeography. Mammalia 66, 495523.

Dobigny, G., Granjon, L., Aniskin, V., Bâ, K. \& Volobouev, V. (2003). A new sibling species of Taterillus (Rodentia, Gerbillinae) from West Africa. Mammal. Biol. 68, 299-316.

Duncan, J.F., Irsiana, R. \& Chang, A. (1974). Karyotypes of five taxa of Rattus (Rodentia, Muridae) from Indonesia. Cytologia 39, 295-302.

Duplantier, J.M., Britton-Davidian, J. \& Granjon, L. (1990). Chromosomal characterization of three species of the genus Mastomys in Senegal. Z. zool. Syst. Evolut. Forsch. 28, 289-298.

Evans, E.P., Breckon, G. \& Ford, C.E. (1963). An air-drying method for meiotic preparations from mammalian testes. Cytogenetics 3, 289-294.

Gadi, I. K. \& Sharma, T. (1983). Cytogenetic relationships in Rattus, Cremnomys, Millardia, Nesokia and Bandicota. Genetica 61, 21-40.

Granjon, L. \& Dobigny, G. (2003). Chromosomally characterised murid rodents from the edges of Lake Chad: evidence for an African biogeographical crossroads, or a centre of endemism? Mammal Rev. 33, 77-91.

Hoffman, S.L., Subramanian, G.M., Collins F.H. \& Venter J.C. (2002). Plasmodium, human and Anopheles genomics and malaria. Nature 415, 702.

Lecompte, E., Brouat, C., Duplantier, J.M., Galan, G., Granjon, L., Loiseau, A., Mouline, K. \& Cosson, J.F. (2005). Molecular identification of four cryptic species of Mastomys (Rodentia, Murinae). Biochem. Syst. Ecol. 33, 681-689.

Lecompte, E., Fichet-Calvet, E., Daffis, S. Koulema, K., Sylla, O., Kourouma, F., Doré, A., Soropogui, B., Aniskin, V., Allali, B., Kouassi Kan, S., Lalis, A., Koivogui, L., Günther, Denys, C. \& ter Meulen, J. (2006). Mastomys natalensis and Lassa fever, West Africa. Emerg. Infect. Dis. 12, 178-183. 
Lee, M.R. \& Elder, F.F.B. (1980). Yeast stimulation of bone marrow mitosis for cytogenetic investigations. Cytogenet. Cell Genet. 26, 36-40.

Markvong, A., Marshall, J. \& Gropp, A. (1973). Chromosomes of rats and mice of Thailand. Nat. Hist. Bull. Siam Soc. 25, 23-40.

Marshall, J.T. Jr. (1977). Family Muridae: Rats and mice. In Mammals of Thailand: 396-487. (Eds). Lekagul, B. \& McNeely, J.A.: Association for the Conservation of Wildlife, Sahakarnbhat Co., Bangkok, Thailand.

Michaux, J. R., Kinet, S., Filipucci, M.G., Libois, R., Besnard, A. \& Catzeflis, F. (2001). Molecular identification of three sympatric species of wood mice (Apodemus sylvaticus, A. flavicollis, A. alpicola) in Western Europe (Muridae, Rodentia). Mol. Ecol. Notes 1, 260263.

Mills, J.N. \& Childs, J.E. (1998). Ecologic studies of rodent reservoirs: their relevance for human health. Emerg. Infect. Dis. 4, 529-537.

Moritz, C. (2002). Strategies to protect biological diversity and the evolutionary processes that sustain it. Syst. Biol. 51, 238-254.

Motokawa, M., Lu, K.H., Harada, M. \& Lin, L.K. (2001). New records of the Polynesian rat Rattus exulans (Mammalia: Rodentia) from Taiwan and the Ryukyus. Zool. Stud. 40, 299304.

Musser, G. G. (1981). Notes on systematics of Indo-Malayan murid rodents, and descriptions of new genera and species from Ceylon, Sulawesi, and the Philippines. Bull. Amer. Mus. Nat. Hist. 168, 225-334.

Musser, G. G. \& Newcomb, C. (1983). Malaysian murids and the giant rat of Sumatra. Bull. Amer. Mus. Nat. Hist. 174, 327-598.

Raman, R. \& Sharma, T. (1972). Similarity in karyotypes of Rattus rattus with 38 chromosomes from India and other parts of the World. Experientia 28, 1365-1377. 
542 Rambau, R. V., Stanyon, R. and Robinson, T. J. (2003). Molecular genetics of Rhabdomys

543 pumilio subspecies boundaries: mtDNA phylogeography and karyotypic analysis by

544 fluorescence in situ hybridization (FISH). Mol Phylogenet Evol 28, 564-575.

545 Reynes, J.M., Soares, J.L., Hüe, T., Bouloy, M., Sun, S., Kruy, S.L., Flye Sainte Marie, F. \&

546 Zeller, H. (2003). Evidence of the presence of Seoul virus in Cambodia. Microbes Infect. 5,

$547 \quad 769-773$.

548 Rickart, E. A. \& Musser, G.G. (1993). Philippine rodents: chromosomal characteristics and

549 their significance for phylogenetic inference among 13 species (Rodentia, Muridae, $550 \quad$ Murinae). Amer. Mus. Novit. 3064.

551 Robins J.H., McLenachan, P.A., Phillips, M.J., Craig, L. Ross' H.A. \& Matisoo-Smith ${ }^{\mathrm{a}}$, E. 552 (2008). Dating of divergences within the Rattus genus phylogeny using whole 553 mitochondrial genomes. Mol. Phylogenet. Evol. 49, 460-466.

554 Robinson, T.J., Ruiz-Herrera, A. \& Avise, J.C. (2008). Hemiplasy and homoplasy in the 555 karyotypic phylogenies of mammals. Proc. Nat. Acad. Sci. USA 105, 14477-14481.

556 Sites, J.W. Jr \& Marshall, J.C. (2003). Delimiting species: a Renaissance issue in systematic $557 \quad$ biology. Tr. Ecol. Evol. 18, 462-470.

558 Seabright, M. (1971). A rapid banding technique for human chromosome. Lancet 2, 971-972.

559 Sumner, A.T. (1972). A simple technique for demonstrating centromeric heterochromatin. $560 \quad$ Exp. Cell Res. 75, 304-306.

561 Tsuchiya, K., Yosida, T.H., Moriwaki, K., Ohtani, S., Kulta-Uthai, S. \& Sudto, P. (1979).

562 Karyotypes of twelve species of small mammals from Thailand. Report Hokkaido Inst. $563 \quad$ Public Health 29, 26-29.

564 Veyrunes, F., Catalan, J., Sicard, B., Robinson, T.J., Duplantier, J.M., Granjon, L., Dobigny, 565 G. \& Britton-Davidian, J. (2004). Autosome and sex chromosome diversity among the 
African pygmy mice, subgenus Nannomys (Murinae; Mus). Chromosome Res. 12, 369382.

568 Volobouev, V., Ducroz, J.F., Aniskin, V., Britton-Davidian, J., Castiglia, R., Dobigny, G.,

569 Granjon, L., Lombard, M., Sicard, B. \& Capanna, E. (2002). Chromosomal 570 characterisation of Arvicanthis species (Rodentia: Murinae) from Western and Central 571 Africa: implications on taxonomy. Cytogenet. Genome Res. 96, 250-260.

572 Wang, J.X., Zhao, X.F., Koh, H.S., Deng, Y. \& Qi, H.Y. (2003). Chromosomal

573 polymorphisms due to heterochromatin growth and pericentric inversions in white-bellied

574 rat, Niviventer confucianus, from China. Hereditas 138, 59-64.

575 Wilson, D.E. \& Reeder, D.A.M. (2005). Mammal species of the World: a taxonomic and 576 geographic reference. The John Hopkins University Press, Baltimore, USA.

577 Yong, H.S. (1968). Karyotype of four Malayan rats (Muridae, genus Rattus Fischer). $578 \quad$ Cytologia 33, 174-80.

579 Yong, H.S. (1969). Karyotypes of Malayan rats (Rodentia, Muridae, genus Rattus Fischer). $580 \quad$ Chromosoma 27, 245-267.

581 Yong, H.S. (1973). Chromosomes of the pencil-tailed tree-mouse, Chiropodomys gliroides 582 (Rodentia, Muridae). Malay. Nat. J. 26, 159-162.

583 Yong, H.S., Dhaliwal, S.S. \& Lim, L. (1982). Karyotypes of Hapalomys and Pithecheir 584 (Rodentia, Muridae) from Peninsular Malaysia. Cytologia 47, 535-538.

585 Yong, H.S. (1983). Heterochromatin blocks in the karyotype of the pencil-tailed tree-mouse, 586 Chiropodomys gliroides (Rodentia, Muridae). Experientia 39, 1039-1040.

587 Yosida, T.H., Tsuchiya, K. \& Moriwaki, K. (1971). Frequency of chromosome polymorphism 588 in Rattus rattus collected in Japan. Chromosoma 33, 33-40. 
589 Yosida, T.H., Tsuchiya, K. \& Moriwaki, K. (1971). Karyotypic differences of black rats,

590 Rattus rattus, collected in various localities of East and Southeast Asia and Oceania.

$591 \quad$ Chromosoma 33, 252-267.

592 Yosida, T.H. (1973). Evolution of karyotypes and differentiation in 13 Rattus species.

593 Chromosoma 40, 285-297.

594 Yosida, T.H., Kato, H., Tsuchiya, K., Sagai, T. \& Moriwaki, K. (1974). Cytogenetical survey

595 of black rats, Rattus rattus, in Southwest and Central Asia, with special regard to the

596 evolutionary relationship between three geographical types. Chromosoma 45, 99-109.

597 Yosida, T.H. \& Sagai, T. (1975). Variation in C-bands in the chromosomes of several $598 \quad$ subspecies of Rattus rattus. Chromosoma 50, 283-300.

599 Yosida, T.H. (1977a). Frequencies of chromosome polymorphism in pairs $\mathrm{n}^{\circ} 1,9$ and 13 in

600 three geographical variants of black rats, Rattus rattus. Chromosoma 60, 391-398.

601 Yosida, T.H. (1977b). Supernumerary chromosomes in the black rat (Rattus rattus) and their 602 distribution in three geographic variants. Cytogenet. Cell Genet. 18, 149-159.

603

604 
606

607 Table 1: Specimens investigated in the present study. Those that were diagnosed using DNA 608 sequencing are noted as "+" in the Id. DNA column. Individual numbers refer to the CBGP 609 Asian rodent collection (resp. Y. Chaval, Montpellier, France). Sex, origin, diploid (2n) and 610 autosomal fundamental $(\mathrm{NFa})$ numbers, type of biological material (bm: bone marrow; cc: 611 cell culture), sex chromosomes morphology (X/Y) as well as number of B-chromosomes (Bs) 612 are provided for each animal.

613

614 Table 2: Chromosomal polymorphism observed for pairs 1, 9 and 13 (sensu Yosida and 615 colleagues; see text for details) in the Rattus specimens investigated here. $\mathrm{M}$ and A 616 correspond to meta-/submetacentric and acrocentric morphs, respectively. Like for Table 1, 617 individual numbers refer to the CBGP Asian rodent collection (resp. Y. Chaval, Montpellier, 618 France).

620 Fig. 1: G-banded karyotype (a) and C-banded metaphase (b) of a male Leopolodamys 621 edwardsi ( $\left.\mathrm{n}^{\circ} \mathrm{R} 5239\right)$. Arrows indicate C-positive intercalary bands and minute $\mathrm{Y}$.

622

623 Fig. 2: G-banded karyotype (a) and C-banded metaphase (b) of a female Niviventer fulvescens $624\left(n^{\circ} \mathrm{R} 4519\right)$.

625

626 Fig. 3: G-banded karyotype (a) and C-banded metaphase (b) of a male Maxomys surifer 627 ( $\left.\mathrm{n}^{\circ} \mathrm{R} 4404\right)$. The arrow indicates the C-positive Y chromosome. 
629 Fig. 4: G-banded karyotype (a) and C-banded metaphase (b) of a female Berylmys berdmorei $630 \quad\left(n^{\circ} \mathrm{R} 4406\right)$.

631

632 Fig. 5: G-banded karyotype (a) and C-banded metaphase (b) of a male Berylmys bowersi $633\left(\mathrm{n}^{\circ} \mathrm{R} 4400\right)$. The arrow indicates the $\mathrm{C}$-positive $\mathrm{Y}$ chromosome.

634

635 Fig. 6: G-banded karyotype (a) and C-banded metaphase (b) of a female Bandicota savilei $636\left(\mathrm{n}^{\circ} \mathrm{R} 4408\right)$. Arrows indicate the X chromosomes.

637

638 Fig. 7: G-banded karyotype (a) and C-banded metaphase (b) of a male Hapalomys delacouri 639 ( $\left.\mathrm{n}^{\circ} \mathrm{R} 5237\right)$. The arrow indicates the C-negative $\mathrm{Y}$ chromosome.

640

641 Fig. 8: C-banded metaphase of a male Chiropodomys gliroides ( $\left.{ }^{\circ} \mathrm{R} 5238\right)$.

642

643 Fig. 9: Conventionally stained (a) and C-banded (b) metaphases of one female Mus cooki $644\left(\mathrm{n}^{\circ} \mathrm{R} 4105\right)$ showing the strongly C-positive and metacentric B-chromosome (arrows). 645 


\begin{tabular}{|c|c|c|c|c|c|c|c|c|c|}
\hline \multirow[t]{2}{*}{ Species } & \multirow{2}{*}{$\begin{array}{c}\text { Id. } \\
\text { DNA }\end{array}$} & \multicolumn{3}{|c|}{ Individuals } & \multicolumn{5}{|c|}{ Cytogenetics } \\
\hline & & individual & $\operatorname{sex}$ & origin & material & $2 \mathbf{N}$ & $\mathbf{X} / \mathbf{Y}$ & NFa & Bs \\
\hline Menetes berdmorei & - & R4002 & $\mathrm{F}$ & Kalasin & $\mathrm{bm}$ & 38 & & 72 & \\
\hline \multirow[t]{5}{*}{ Rattus losea } & + & R4203 & $\mathrm{F}$ & Phrae & $\mathrm{bm}$ & 42 & A & 58 & \\
\hline & + & R4229 & M & Loei & $\mathrm{bm}$ & 42 & $\mathrm{~A} / \mathrm{A}$ & 58 & \\
\hline & + & $\mathrm{R} 4230$ & M & Loei & $\mathrm{bm}$ & 42 & $\mathrm{~A} / \mathrm{A}$ & 57 & \\
\hline & + & $\mathrm{R} 4260$ & $\mathrm{~F}$ & Loei & $\mathrm{bm}$ & 42 & A & 58 & \\
\hline & + & $\mathrm{R} 4724$ & $\mathrm{~F}$ & Loei & $\mathrm{cc}$ & 42 & A & 56 & \\
\hline \multirow[t]{13}{*}{ Rattus tanezumi } & + & $\mathrm{R} 4113$ & M & Loei & bm & 42 & $\mathrm{~A} / \mathrm{A}$ & 54 & \\
\hline & + & R4481 & $\mathrm{F}$ & Phrae & $\mathrm{bm}$ & 42 & A & 55 & \\
\hline & + & $\mathrm{R} 4003$ & $\mathrm{~F}$ & Kalasin & $\mathrm{bm}$ & 42 & A & 57 & \\
\hline & - & R4008 & $\mathrm{M}$ & Kalasin & $\mathrm{bm}$ & 42 & $\mathrm{~A} / \mathrm{A}$ & 55 & \\
\hline & + & R4016 & $\mathrm{F}$ & Phrae & $\mathrm{bm}$ & 42 & A & 52 & \\
\hline & - & R4096 & $\mathrm{F}$ & Loei & $\mathrm{bm}$ & 42 & A & 52 & \\
\hline & - & $\mathrm{R} 4145$ & $\mathrm{~F}$ & Phrae & $\mathrm{bm}$ & 42 & A & 54 & \\
\hline & + & $\mathrm{R} 4182$ & $\mathrm{~F}$ & Phrae & $\mathrm{bm}$ & 42 & A & 56 & \\
\hline & + & $\mathrm{R} 4436$ & M & Phrae & $\mathrm{bm}$ & 43 & $\mathrm{~A} / \mathrm{A}$ & $59 ?$ & 1 \\
\hline & - & $\mathrm{R} 4447$ & $\mathrm{M}$ & Phrae & $\mathrm{bm}$ & 42 & $\mathrm{~A} / \mathrm{A}$ & 55 & \\
\hline & - & $\mathrm{R} 4450$ & $\mathrm{M}$ & Phrae & $\mathrm{bm}$ & 42 & $\mathrm{~A} / \mathrm{A}$ & 56 & \\
\hline & - & $\mathrm{R} 4542$ & $\mathrm{~F}$ & Loei & $\mathrm{bm}$ & 42 & A & 56 & \\
\hline & + & $\mathrm{R} 4075$ & $\mathrm{M}$ & Loei & $\mathrm{bm}$ & 42 & $\mathrm{~A} / \mathrm{A}$ & 57 & \\
\hline \multirow[t]{8}{*}{ Rattus exulans } & - & $\mathrm{R} 4033$ & $\mathrm{~F}$ & Phrae & $\mathrm{bm}$ & 42 & A & 58 & \\
\hline & - & R4035 & $\mathrm{F}$ & Phrae & $\mathrm{bm}$ & 42 & A & 59 & \\
\hline & - & $\mathrm{R} 4100$ & $\mathrm{~F}$ & Loei & $\mathrm{bm}$ & 42 & A & 59 & \\
\hline & + & R4103 & M & Loei & $\mathrm{bm}$ & 42 & $\mathrm{~A} / \mathrm{A}$ & 58 & \\
\hline & - & R4104 & $\mathrm{M}$ & Loei & $\mathrm{bm}$ & 42 & $?$ & $?$ & \\
\hline & - & R4112 & M & Loei & $\mathrm{bm}$ & 42 & $\mathrm{~A} / \mathrm{A}$ & 54 & \\
\hline & + & $\mathrm{R} 4140$ & $\mathrm{~F}$ & Phrae & $\mathrm{bm}$ & 42 & A & $?$ & \\
\hline & - & $\mathrm{R} 4216$ & $\mathrm{M}$ & Loei & $\mathrm{bm}$ & 42 & $\mathrm{~A} / \mathrm{A}$ & 58 & \\
\hline \multirow[t]{2}{*}{ Bandicota indica } & + & $\mathrm{R} 4000$ & $\mathrm{M}$ & Kalasin & $\mathrm{bm}$ & 45 & $? / ?$ & $?$ & \\
\hline & + & $\mathrm{R} 4265$ & $\mathrm{~F}$ & Loei & $\mathrm{bm}$ & 44 & $?$ & $?$ & \\
\hline \multirow[t]{6}{*}{ Bandicota savilei } & + & $\mathrm{R} 4141$ & M & Phrae & $\mathrm{bm}$ & 43 & $? / ?$ & $?$ & \\
\hline & + & $\mathrm{R} 4142$ & M & Phrae & $\mathrm{bm}$ & 43 & $? / ?$ & $?$ & \\
\hline & + & $\mathrm{R} 4143$ & $\mathrm{M}$ & Phrae & $\mathrm{bm}$ & 45 & $? / ?$ & $?$ & \\
\hline & + & R4017 & $\mathrm{F}$ & Phrae & $\mathrm{bm}$ & 43 & $?$ & $?$ & \\
\hline & + & $\mathrm{R} 4408$ & $\mathrm{~F}$ & Loei & $\mathrm{cc}$ & 43 & $\mathrm{SM}$ & 60 & 1 \\
\hline & + & R4021 & $\mathrm{M}$ & Phrae & $\mathrm{bm}$ & 43 & $? / ?$ & $?$ & \\
\hline \multirow[t]{4}{*}{ Leopoldamys edwardsi } & + & R5239 & M & Loei & $\mathrm{cc}$ & 42 & $\mathrm{~A} / \mathrm{A}$ & 54 & \\
\hline & + & R5240 & M & Loei & $\mathrm{cc}$ & 42 & $\mathrm{~A} / \mathrm{A}$ & 54 & \\
\hline & + & $\mathrm{R} 4070$ & M & Loei & $\mathrm{bm}$ & 42 & $\mathrm{~A} / \mathrm{A}$ & 54 & \\
\hline & + & R4098 & M & Loei & $\mathrm{bm}$ & 42 & $\mathrm{~A} / \mathrm{A}$ & 54 & \\
\hline
\end{tabular}




\begin{tabular}{|c|c|c|c|c|c|c|c|c|c|}
\hline & + & R4222 & $\mathrm{F}$ & Loei & $\mathrm{bm}$ & 42 & A & 54 & \\
\hline Leopoldamys neilli & + & R4477 & $\mathrm{F}$ & Phrae & bm & 44 & $\mathrm{~A} ?$ & 50 & \\
\hline \multirow[t]{6}{*}{ Maxomys surifer } & + & R4099 & M & Loei & $\mathrm{bm}$ & 52 & $\mathrm{~A} / \mathrm{A}$ & 64 & \\
\hline & + & R4107 & M & Loei & $\mathrm{bm}$ & 52 & $\mathrm{~A} / \mathrm{A}$ & 64 & \\
\hline & + & R4108 & M & Loei & $\mathrm{bm}$ & 52 & $\mathrm{~A} / \mathrm{A}$ & 64 & \\
\hline & + & $\mathrm{R} 4223$ & M & Loei & bm & 52 & $\mathrm{~A} / \mathrm{A}$ & 64 & \\
\hline & + & $\mathrm{R} 4259$ & $\mathrm{~F}$ & Loei & $\mathrm{bm}$ & 52 & A & 64 & \\
\hline & + & R4404 & M & Loei & $\mathrm{cc}$ & 52 & $\mathrm{~A} / \mathrm{A}$ & 64 & \\
\hline \multirow[t]{3}{*}{ Niviventer fulvescens } & + & $\mathrm{R} 4071$ & M & Loei & $\mathrm{bm}$ & 46 & $\mathrm{~A} / \mathrm{A}$ & 52 & \\
\hline & + & R4409 & M & Loei & $\mathrm{cc}$ & 44 (rearr.) & & & \\
\hline & + & $\mathrm{R} 4519$ & $\mathrm{~F}$ & Loei & $\mathrm{bm}$ & 46 & $\mathrm{~A}$ & 52 & \\
\hline \multirow[t]{2}{*}{ Berylmys berdmorei } & + & $\mathrm{R} 4266$ & $\mathrm{~F}$ & Loei & $\mathrm{bm}$ & 40 & $\mathrm{~A}$ & 62 & \\
\hline & + & R4406 & $\mathrm{F}$ & Loei & $\mathrm{cc}$ & 41 & A & 64 & 1 \\
\hline \multirow[t]{2}{*}{ Berylmys bowersi } & + & $\mathrm{R} 4102$ & $\mathrm{~F}$ & Loei & $\mathrm{bm}$ & 40 & $\mathrm{~A}$ & 62 & \\
\hline & + & $\mathrm{R} 4400$ & M & Loei & $\mathrm{cc}$ & 40 & $\mathrm{~A} / \mathrm{A}$ & 62 & \\
\hline Hapalomys delacouri & + & $\mathrm{R} 5237$ & M & Loei & $\mathrm{cc}$ & 48 & $\mathrm{M} / \mathrm{A}$ & 92 & \\
\hline Chiropodomys gliroides & + & $\mathrm{R} 5238$ & M & Loei & $\mathrm{cc}$ & 42 & $\mathrm{~A} / \mathrm{A}$ & 40 & \\
\hline \multirow[t]{11}{*}{ Mus cooki } & + & R4074 & M & Loei & bm & 40 & $\mathrm{~A} / \mathrm{A}$ & 38 & \\
\hline & + & $\mathrm{R} 4105$ & $\mathrm{~F}$ & Loei & $\mathrm{bm}$ & 41 & $\mathrm{~A}$ & 40 & 1 \\
\hline & + & $\mathrm{R} 4215$ & M & Loei & bm & 40 & $\mathrm{~A} / \mathrm{A}$ & 38 & \\
\hline & + & R4097 & M & Loei & $\mathrm{bm}$ & 40 & $\mathrm{~A} / \mathrm{A}$ & 38 & \\
\hline & + & $\mathrm{R} 4101$ & $\mathrm{~F}$ & Loei & $\mathrm{bm}$ & 40 & $\mathrm{~A}$ & 38 & \\
\hline & + & R4106 & M & Loei & $\mathrm{bm}$ & 40 & $\mathrm{~A} / \mathrm{A}$ & 38 & \\
\hline & + & R4110 & M & Loei & bm & 40 & $\mathrm{~A} / \mathrm{A}$ & 38 & \\
\hline & + & R4111 & $\mathrm{F}$ & Loei & bm & 40 & A & 38 & \\
\hline & + & $\mathrm{R} 4146$ & $\mathrm{~F}$ & Phrae & $\mathrm{bm}$ & 40 & A & 38 & \\
\hline & + & R4264 & F & Loei & $\mathrm{bm}$ & 40 & $\mathrm{~A}$ & 38 & \\
\hline & + & R4147 & $\mathrm{F}$ & Phrae & $\mathrm{bm}$ & 41 & A & 39 & 1 \\
\hline \multirow[t]{2}{*}{ Mus cervicolor } & + & R4109 & M & Loei & bm & 40 & $\mathrm{~A} / \mathrm{A}$ & 38 & \\
\hline & + & R4183 & M & Phrae & $\mathrm{bm}$ & 40 & $\mathrm{~A} / \mathrm{A}$ & 38 & \\
\hline Mus caroli & + & $\mathrm{R} 4240$ & $\mathrm{~F}$ & Loei & bm & 40 & A & 38 & \\
\hline
\end{tabular}


651 Table 2

652

\begin{tabular}{|c|c|c|c|c|}
\hline \multirow[t]{2}{*}{ Species } & \multirow[t]{2}{*}{ Individuals } & \multicolumn{3}{|c|}{ Polymorphism in Rattus species } \\
\hline & & pair 1 & pair 9 & pair 13 \\
\hline \multirow[t]{5}{*}{ Rattus losea } & R4203 & MM & MM & AA \\
\hline & R4229 & MM & MM & AA \\
\hline & $\mathrm{R} 4230$ & MM & MM & AA \\
\hline & $\mathrm{R} 4260$ & MM & MM & AA \\
\hline & R4724 & MM & AA & AA \\
\hline \multirow[t]{13}{*}{ Rattus tanezumi } & $\mathrm{R} 4113$ & AA & AA & AA \\
\hline & $\mathrm{R} 4481$ & AA & AM & AA \\
\hline & $\mathrm{R} 4003$ & AM & $\mathrm{AM}$ & $\mathrm{AM}$ \\
\hline & $\mathrm{R} 4008$ & AA & $\mathrm{AM}$ & AA \\
\hline & R4016 & AA & $\mathrm{AA}$ & AA \\
\hline & R4096 & AA & AA & AA \\
\hline & R4145 & AA & AA & AA \\
\hline & R4182 & $\mathrm{AA}$ & MM & $\mathrm{AA}$ \\
\hline & R4436 & AA & $?$ & $?$ \\
\hline & R4447 & $\mathrm{AM}$ & $\mathrm{AA}$ & AA \\
\hline & R4450 & $\mathrm{AM}$ & $\mathrm{AM}$ & AA \\
\hline & $\mathrm{R} 4542$ & AA & MM & AA \\
\hline & R4075 & $\mathrm{AM}$ & MM & AA \\
\hline \multirow[t]{8}{*}{ Rattus exulans } & R4033 & MM & MM & $\mathrm{AA}$ \\
\hline & R4035 & MM & MM & AA \\
\hline & R4100 & MM & MM & $\mathrm{AM}$ \\
\hline & R4103 & MM & MM & AA \\
\hline & R4104 & $?$ & $?$ & $?$ \\
\hline & R4112 & $\mathrm{MM}$ & AA & $\mathrm{AA}$ \\
\hline & R4140 & $?$ & $?$ & $?$ \\
\hline & R4216 & MM & $\mathrm{AA}$ & MM \\
\hline
\end{tabular}


653 Fig. 1

654

655
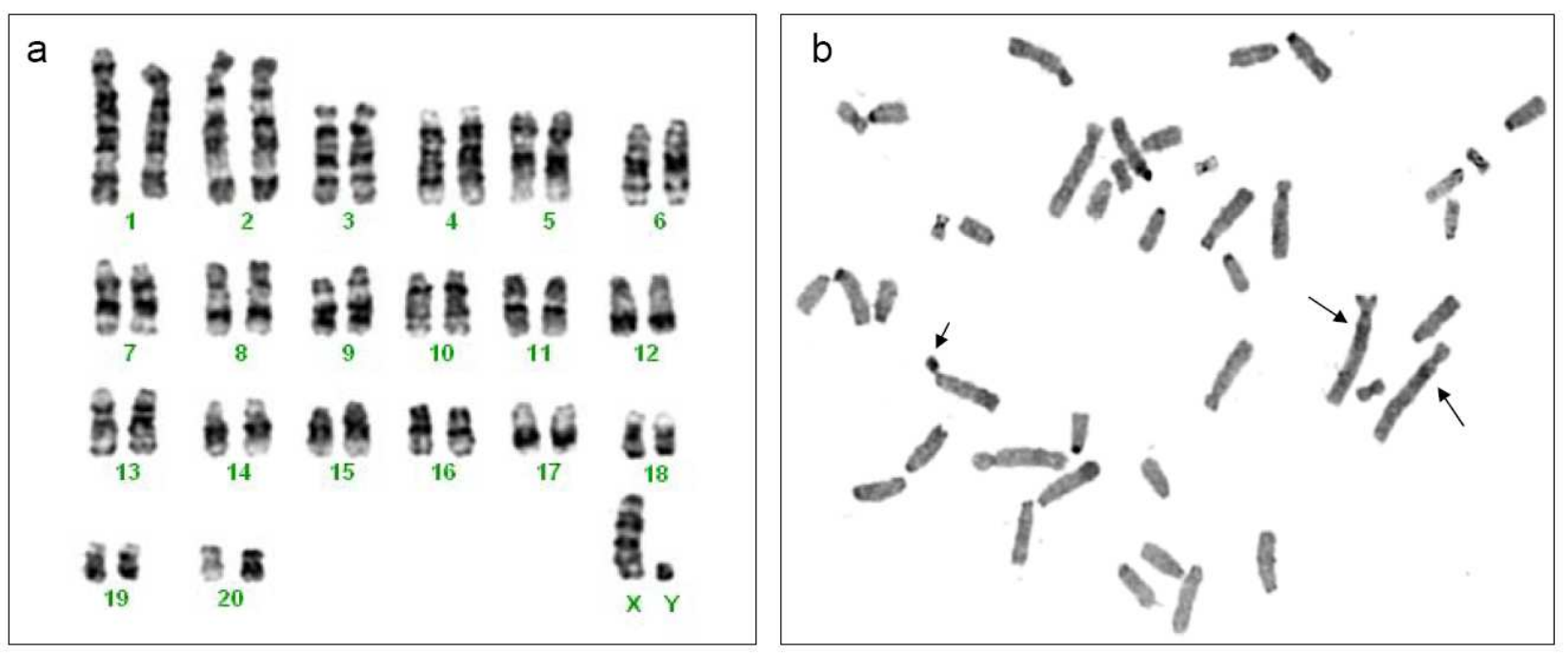

656

657

658 Fig. 2

$$
\begin{aligned}
& \text { 量 }
\end{aligned}
$$

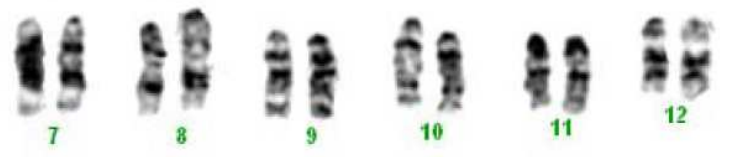

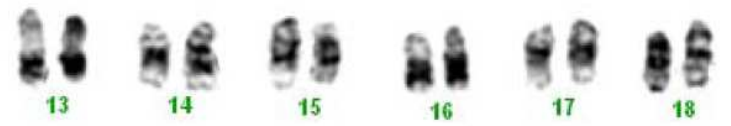

$$
\begin{aligned}
& \text { 蛅 }
\end{aligned}
$$

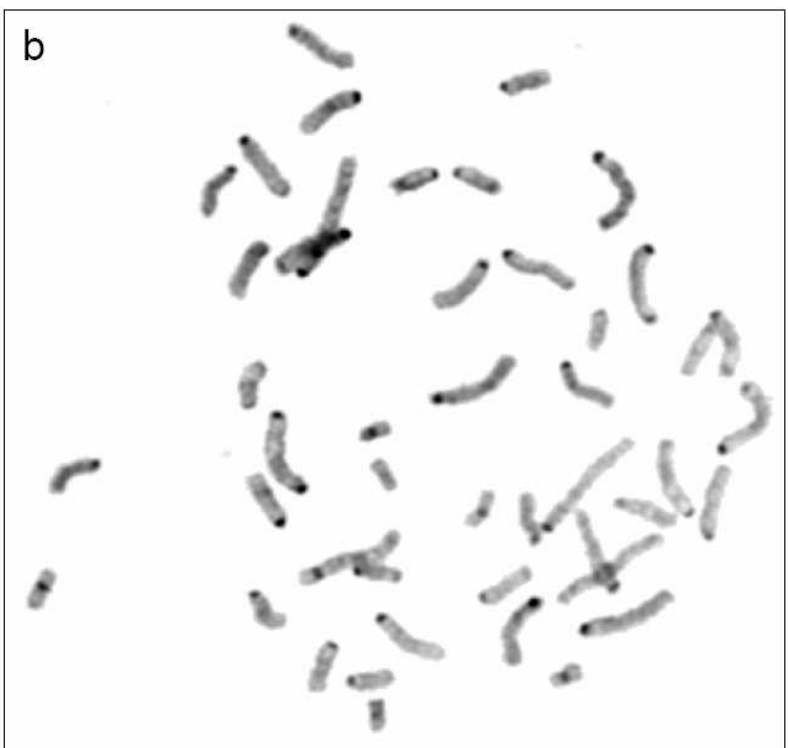

659 
Fig. 3

661

662
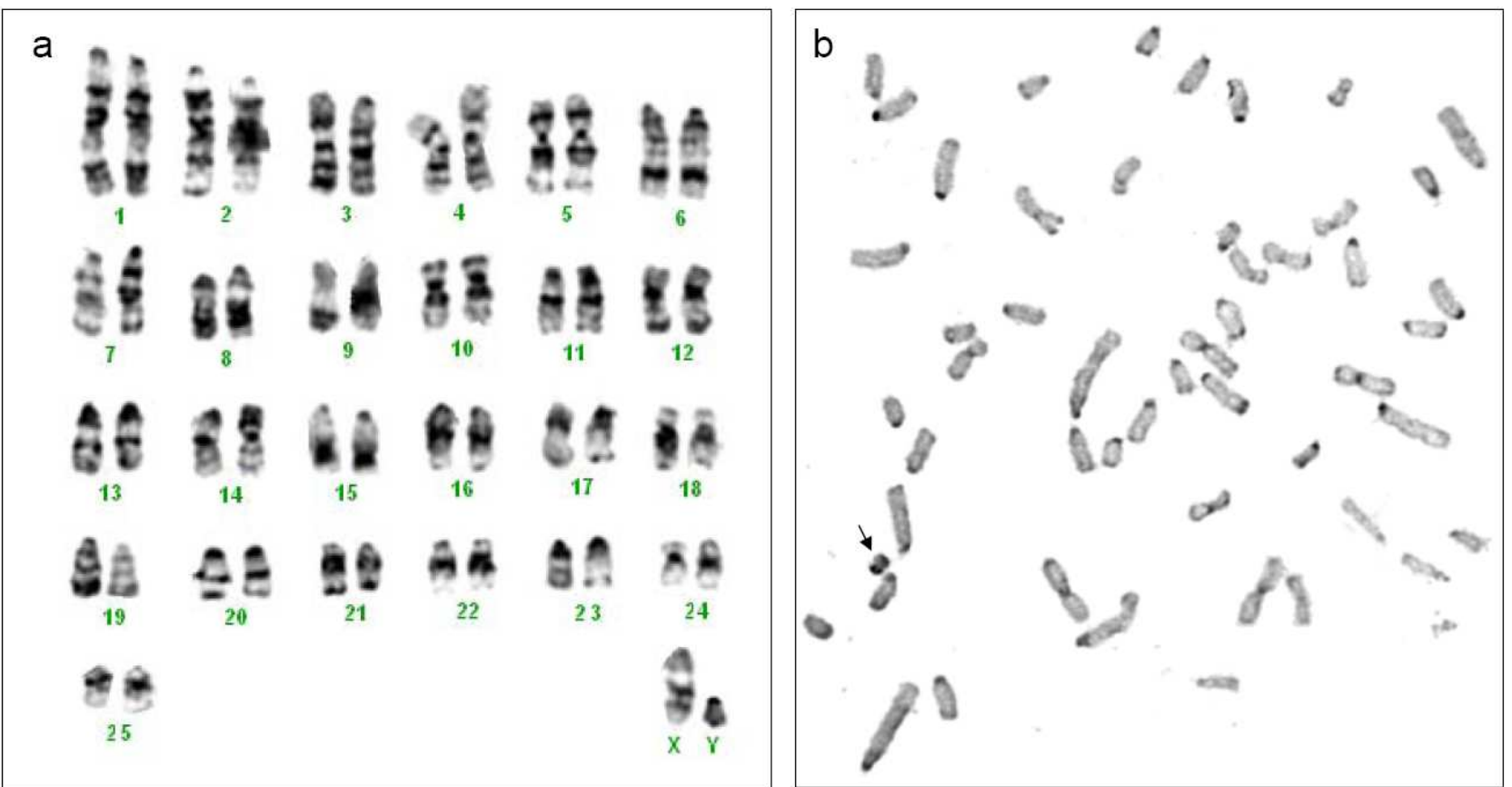

663

664

665

666 Fig. 4

667

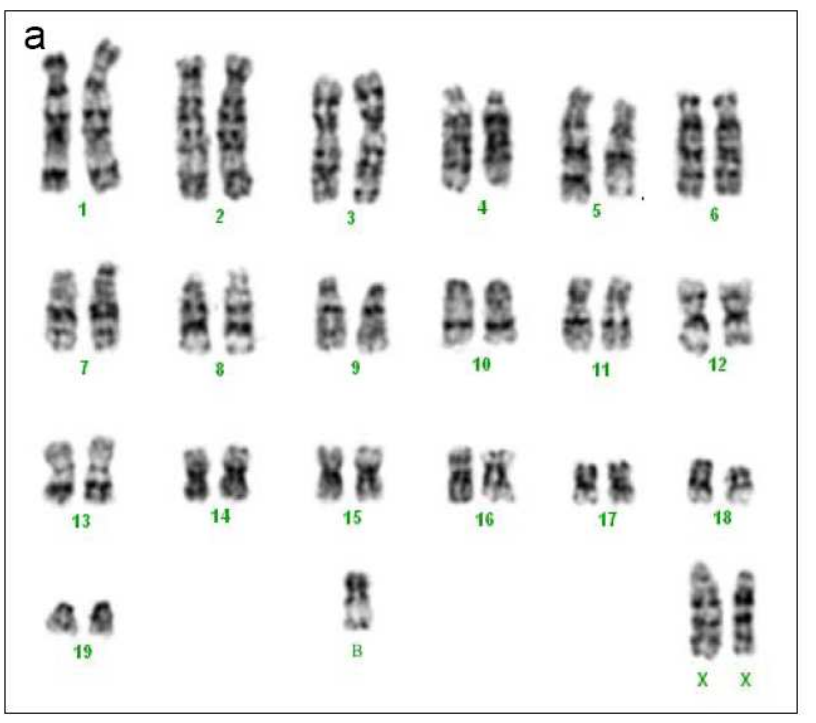

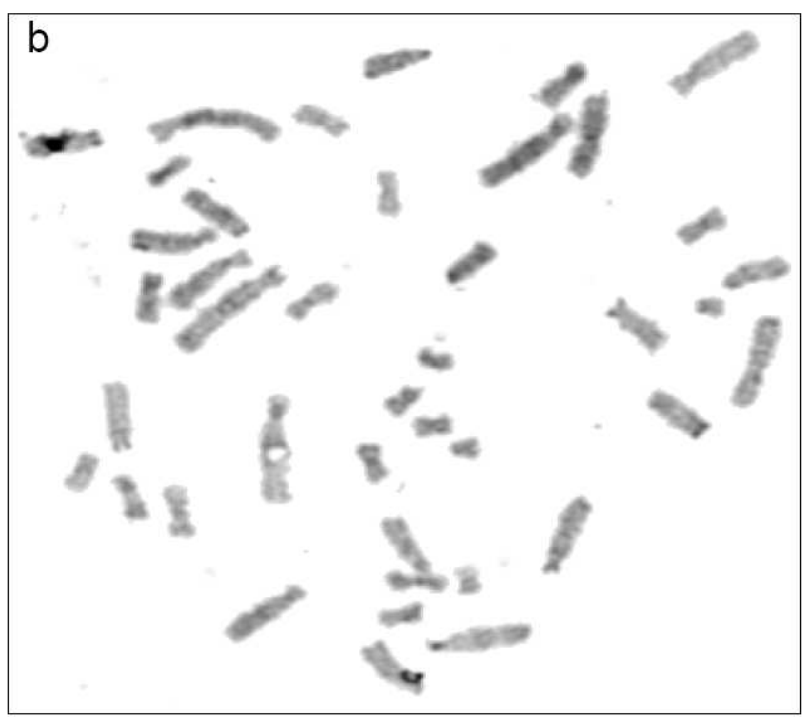


Fig. 5

670
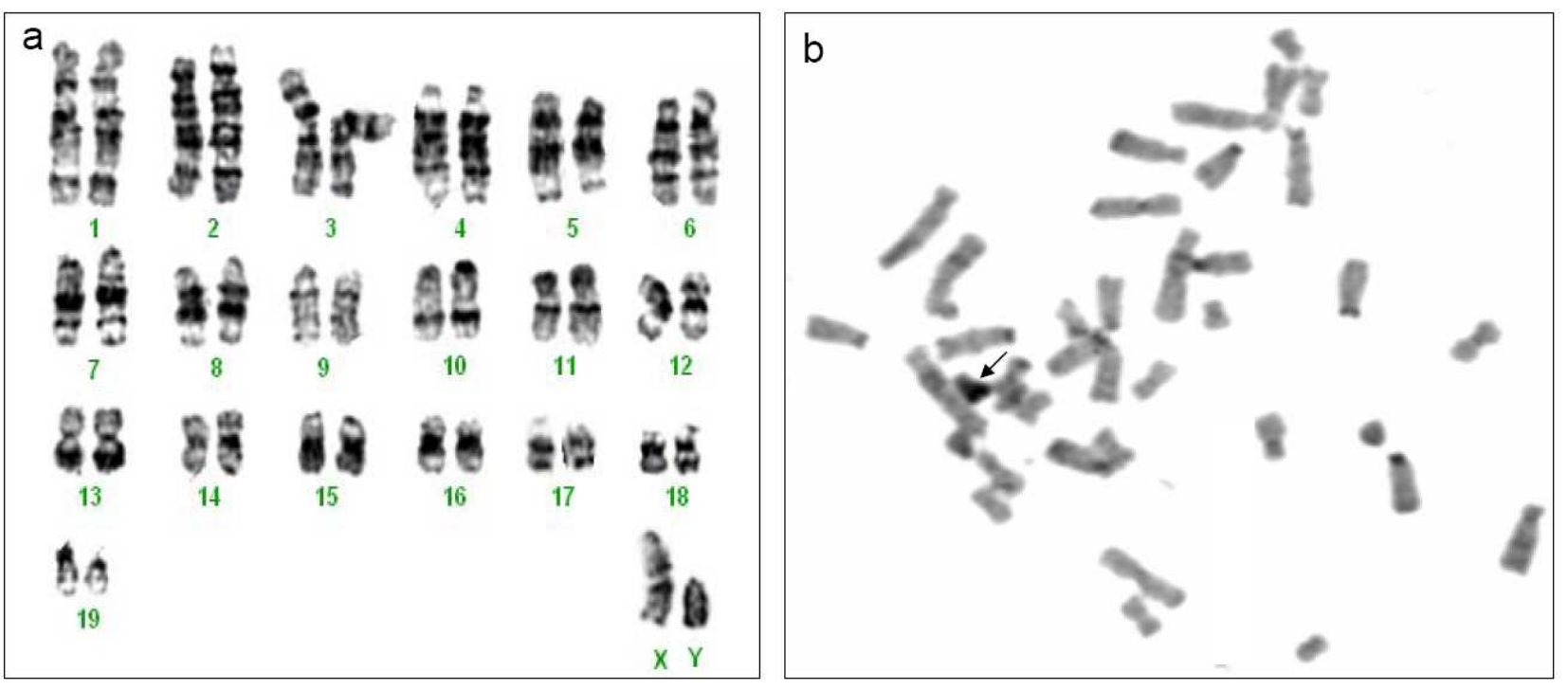

671

672

673 Fig. 6

674
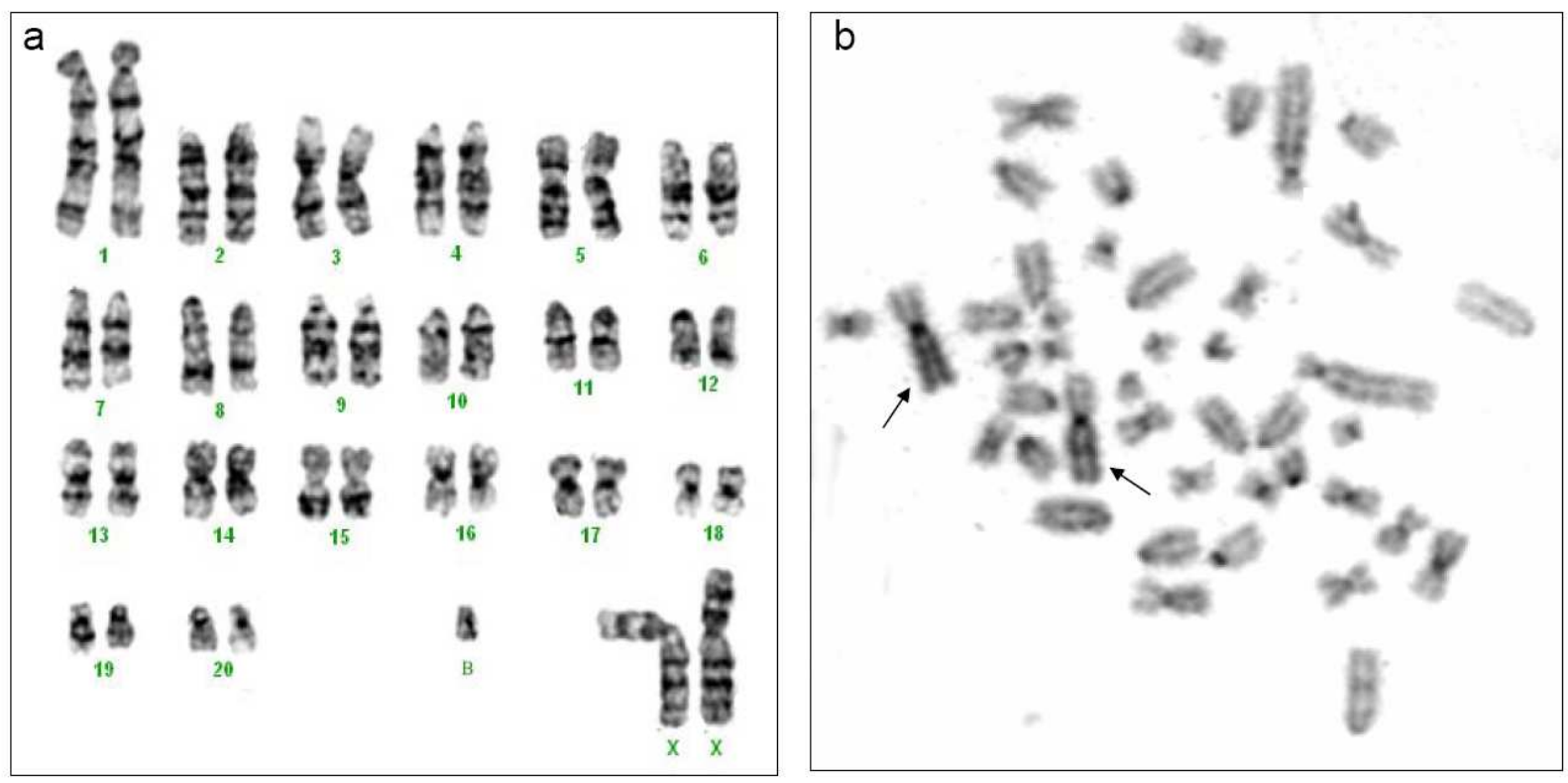

675 
677

$678 \quad$ Fig. 7
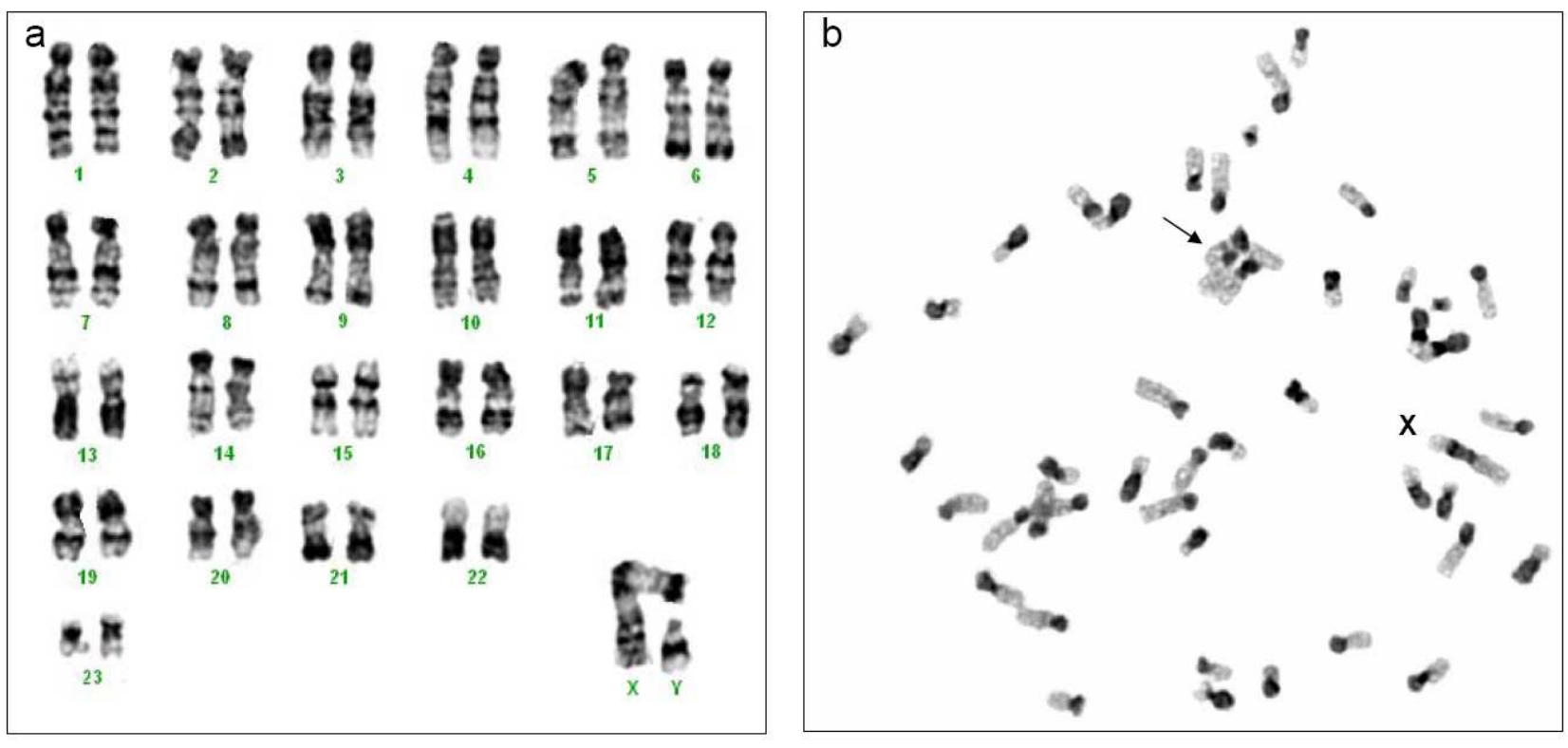

679

680

$681 \quad$ Fig. 8

682

683

684

685

686

687

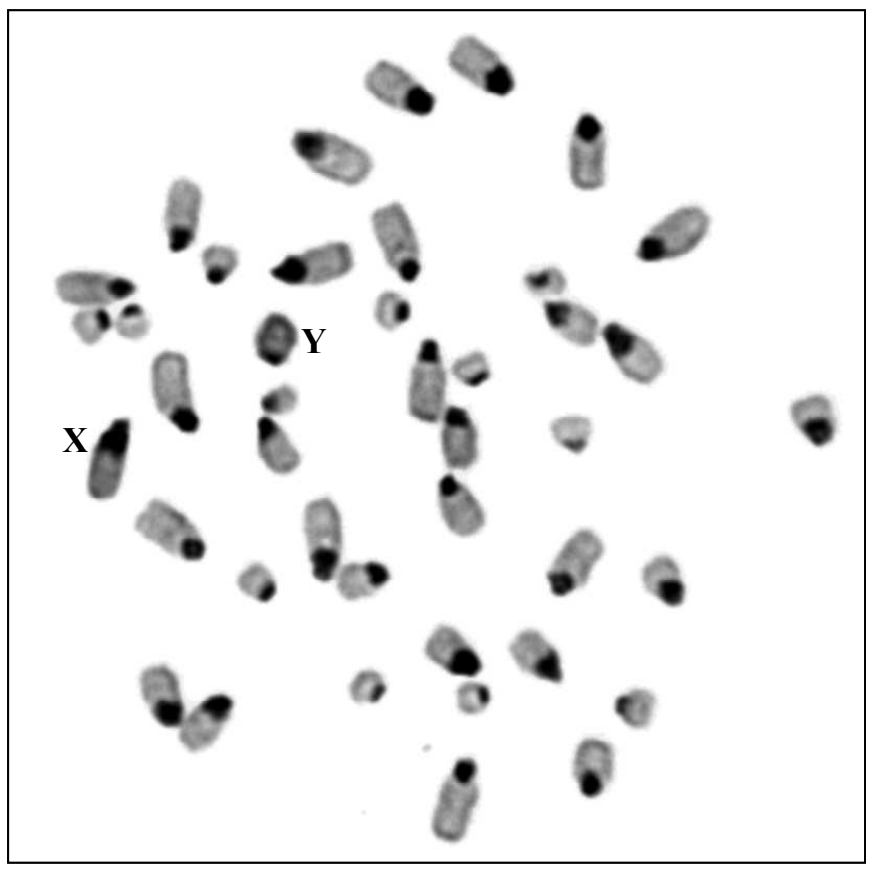


Fig. 9

689

690

691

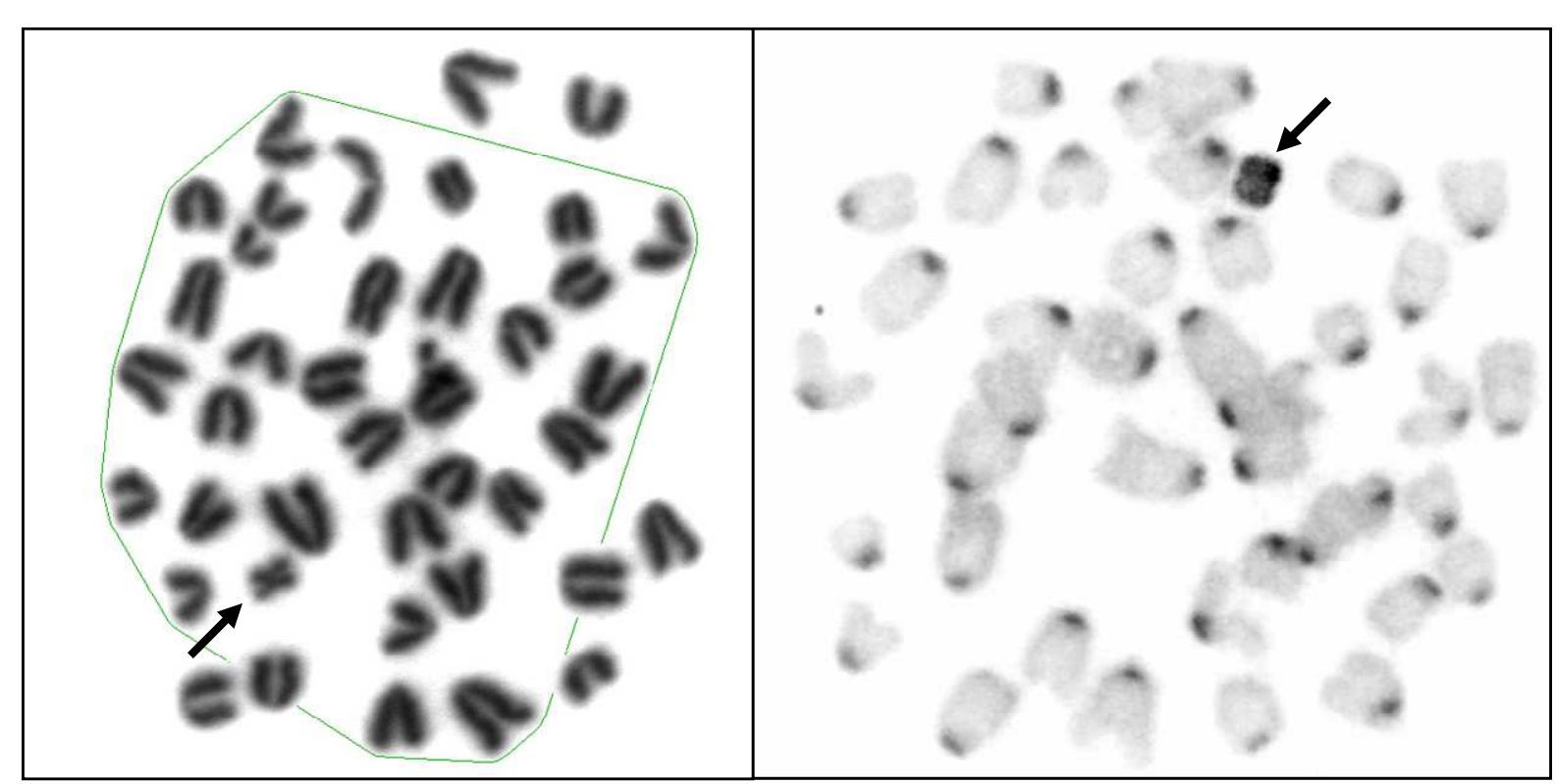

